\title{
Insights from complex aortic surgery with a Streamliner device for aortic arch repair (STAR)
}

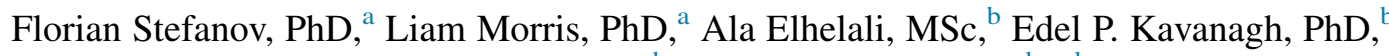 \\ Violet Lundon, BSc, ${ }^{\mathrm{c}}$ Niamh Hynes, MD, ${ }^{\mathrm{b}}$ and Sherif Sultan, $\mathrm{MD}^{\mathrm{b}, \mathrm{c}, \mathrm{d}}$
}

\begin{abstract}
Objective: Aortic arch aneurysms and thoracoabdominal aortic arch aneurysms are technically challenging to manage by established surgical and endovascular methods. The Streamliner Multilayer Flow Modulator device (Cardiatis, Isnes, Brussels, Belgium) offers an unorthodox option for these high-risk cases. The Streamliner device for aortic arch repair (STAR) study investigated complex aneurysm cases managed by the Streamliner Multilayer Flow Modulator device and offers an analytic solution for a clinical dilemma.
\end{abstract}

Methods: Six cases were included, with a 1-year follow-up, comprising 4 pure arch aneurysms and 2 thoracoabdominal aortic arch aneurysms Crawford type I, from a multicenter database hosted by the Streamliner Multilayer Flow Modulator Global Registry. A total of $50 \%$ of cases were performed under instructions for use. All were American Society of Anesthesiology IV and originated from zone 0 . All cases were computationally analyzed, which consisted of (1) simulating the treatment on the basis of the postoperative data, (2) repositioning the stents for the failed technical cases, and (3) assessing the effects of overlapping devices on branch patency.

Results: Correct device placement induced aneurysm flow streamlining, which reduced the dynamic pressure by $23 \%$ to $66 \%$, whereas incorrect placements promoted Failure Mode I with 58\% and 16\% dynamic pressure increases and aneurysm volume expansion up to $23 \%$. Overlapped devices improved distal perfusion by increasing arch branch outflows from $5 \%$ to $24 \%$. The Streamliner Multilayer Flow Modulator device does not benefit a sac volume greater than $400 \mathrm{~cm}^{3}$.

Conclusions: The Streamliner Multilayer Flow Modulator device is a new technology that can manage complex aortic arch aneurysms and thoracoabdominal aortic arch aneurysms with favorable clinical outcomes if it is performed under instructions for use. Careful procedure planning and perioperative virtual stent placement will avoid foreshortening, prevent inadequate stent overlap lengths, and provide insight into the sufficient numbers of required implanted devices. (J Thorac Cardiovasc Surg 2016;152:1309-18)

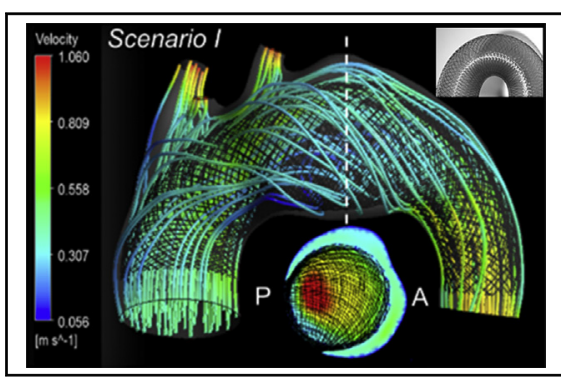

Aneurysm blood flow streamlines and velocity contour plot.

\section{Central Message}

Using the SMFM, a minimum of 3-cm overlap between devices is critical to maintain a constant diameter and profile along the aortic arch, and to improve branch perfusion by $15 \%$

\section{Perspective}

The computational findings from our study may serve as guidelines for future SMFM device repairs regarding the maximum aneurysm volume that can be treated, the device optimum positioning, and the effects that overlapping stents have on branch patency.

See Editorial Commentary page 1319.
The current management of complex aortic arch aneurysms requires a hybrid approach for acceptable early and midterm major morbidity and mortality (12\%); however, there is still a

\footnotetext{
From the ${ }^{a}$ Department of Mechanical and Industrial Engineering, Galway Medical Technologies Centre, Galway Mayo Institute of Technology; ${ }^{\mathrm{b}}$ Department of Vascular and Endovascular Surgery, Galway Clinic; ${ }^{c}$ Department of Vascular and Endovascular Surgery, Western Vascular Institute, Galway University Hospital; and ${ }^{\mathrm{d}}$ National University of Ireland, Galway, Ireland.

Received for publication Feb 23, 2016; revisions received May 24, 2016; accepted for publication June 5, 2016; available ahead of print July 30, 2016.

Address for reprints: Sherif Sultan, MD, Department of Vascular and Endovascular Surgery, Western Vascular Institute, University Hospital Galway, National University of Ireland, Galway, Ireland (E-mail: sherif.sultan@hse.ie). 0022-5223/\$36.00

Copyright (c) 2016 by The American Association for Thoracic Surgery http://dx.doi.org/10.1016/j.jtcvs.2016.06.043
}

high rate of reintervention (24\%) and endoleak (18\%). ${ }^{1}$ The latest endovascular technology currently under clinical trials to treat thoracoabdominal aortic arch aneurysms (TAAAs) involves a disruptive technology in the form of the Streamliner Multilayer Flow Modulator (SMFM) device (Cardiatis, Isnes, Brussels, Belgium) (Video 1). The SMFM is a selfexpandable mesh of cobalt alloy wires interconnected in 5

Scanning this QR code will take you to a video for the article.

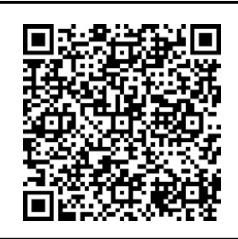




\section{Abbreviations and Acronyms}

IFU = under instructions for use

ILT $=$ intraluminal thrombus

OIFU $=$ outside instructions for use

SMFM $=$ Streamliner Multilayer Flow Modulator

TAAA $=$ thoracoabdominal aortic arch aneurysm

layers (see Central Figure). The wires are extremely flexible with a high kinking and fatigue resistance, and low total porosity. The SMFM design physiologically includes the aneurysm by allowing blood to flow through the mesh to maintain collateral branch patency, while modulating turbulent laminar flow within the device and aneurysm sac. The laminar flow in the aneurysm reduces shear stress on the aneurysm wall and encourages an organized thrombus formation, thereby stabilizing the aneurysm size and reducing the risk of rupture. In complex surgical situations, in which an open or endovascular repair using a branched or fenestrated graft is the only option, the SMFM device could represent a viable treatment alternative. ${ }^{2}$ The SMFM device received Conformité Européenne marking in Europe in October 2010 for use in aortic aneurysm repair. Many of these devices have been placed in patients on compassionate grounds, but there has been little hemodynamic performance documentation of the SMFM mechanism of action. The sizing of SMFM devices for procedure planning is typically done with the EndoSize sizing software (Therenva SAS, Rennes, France) on the patient's computed tomography scans. Cardiatis provides online catalogues with the available thoracoabdominal devices lengths and diameters.

This study computationally assessed the hemodynamic factors associated with the performance of the SMFM device for the preoperative and postoperative treatment of 4 arch aneurysms and 2 TAAAs Crawford type I. The aim of this study is to scrutinize the performance of the SMFM device in patients with arch aneurysms and analyze in what circumstances it can affect aneurysmal wall behavior and branch patency.

\section{MATERIALS AND METHODS \\ Selecting Patient Data}

Six cases comprising preoperative and postoperative treatment of 4 arch aneurysms (cases 1, 2, 4, and 6) and 2 TAAAs Crawford type I (cases 3 and 5) were obtained from a multicenter database hosted by the SMFM Global Registry and are shown in Table 1. Cases presented as multiple arch variants including a bovine aortic arch variant and were treated with the SMFM device, with the number of devices varying from 1 to 3 . The postoperative data were obtained at 1-year follow-up. There were 2 unrelated deaths (cases 2 and 4), with no other reported complications, such as paraplegia, renal failure, stroke, and stent fractures, for all cases. Two of the 6 cases (cases 4 and 6) had severe stent foreshortening at the proximal end that did not comply with the recommended instructions for use (IFU) for adequate device length placement. Case 5 was treated on compassionate grounds because of the overall aneurysm length of $21 \mathrm{~cm}$ and volume greater than $400 \mathrm{~cm}^{3}$, which comprised zones 2 to 5 .

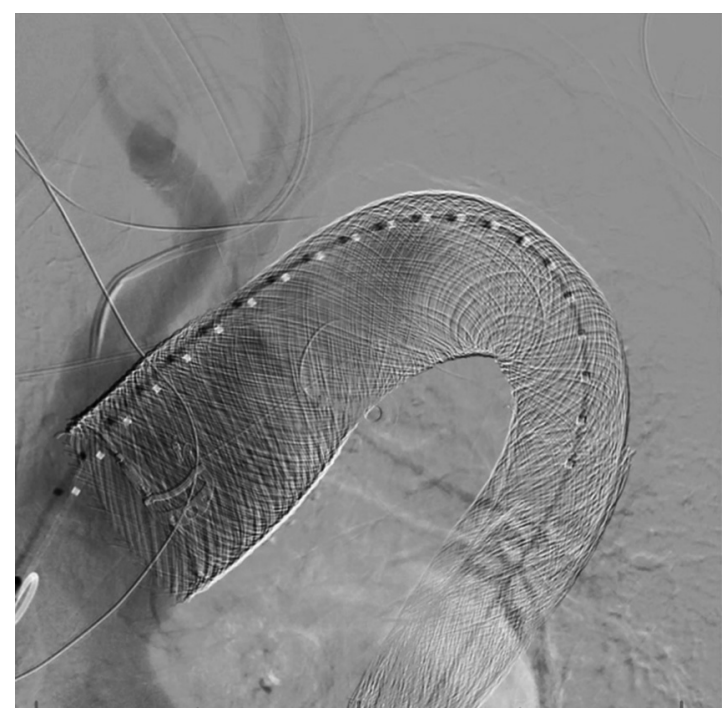

VIDEO 1. Digital subtraction angiography of an SMFM (Cardiatis, Isnes, Brussels, Belgium) device in situ from zone 0 to zone 8 , with enhancement of the supra-aortic branches. Video available at: http://www.jtcvsonline.org/ article/S0022-5223(16)30673-0/addons.

\section{Preoperative and Postoperative Aortic Arch Reconstruction}

All medical images were obtained by computed tomography and saved in Digital Imaging and Communications in Medicine format with a slice thickness and a pixel size ranging from 0.7 to $2 \mathrm{~mm}$ and 0.54 to $0.97 \mathrm{~mm}$, respectively. A semiautomatic segmentation protocol, within Mimics (Materialise, Mimics v17.0, Leuven, Belgium), was used to extract the 3dimensional preoperative and postoperative aortic arch lumens (Figure 1), enclosed by triangulated fitted surfaces as shown for case 1 (Figure 2, A). Table 2 summarizes the geometric features of all preoperative and postoperative cases. The preoperative and postoperative maximum diameters varied from 3.9 to $6.9 \mathrm{~cm}$ and 3.7 to $7.8 \mathrm{~cm}$, respectively, with preoperative and postoperative length variations of 3.9 to $21.0 \mathrm{~cm}$ and 2.6 to $21.6 \mathrm{~cm}$, respectively. There were percentage reductions in maximum diameter and total volume of $4 \%$ to $39 \%$ and $2 \%$ to $23 \%$, respectively, for cases 1 to 4 . Cases 5 and 6 had maximum diameter and total volume increases of $12 \%$ to $15 \%$ and $23 \%$ to $33 \%$, respectively. All cases with reduced aneurysmal sizes had an increase in intraluminal thrombus (ILT) to lumen ratio, whereas the 2 unsuccessful procedures had reductions in this ratio (Table 2).

\section{Reconstructing Streamliner Multilayer Flow Modulator Geometry}

Because of the resolution of the scanned data, it was not possible to reconstruct the stent mesh of the SMFM directly on the basis of the computed tomography scans. Instead, the interlaced geometry was numerically positioned along the segmented device diameters by using the Frenet-Serret frame to define a local coordinate system, along the 3-dimensional center line of each device (Figure 2, B). Table E1 summarizes the length, diameter, and overlap dimensions for each case. Three positions of the SMFM device for computed fluid dynamics blood flow simulations were generated. Simulation I represents the clinical outcomes of all cases based on the follow-up data. Simulation II shows the best SMFM performance that could have been achieved if all devices were used according to the instructions for use. Simulation III investigates the double and triple stent overlapping effects on the arch branches outflows. These simulations were generated as follows: 
TABLE 1. Multicenter clinical data showing status of patients and number of Streamliner Multilayer Flow Modulator (Cardiatis, Isnes, Brussels, Belgium) devices implanted

\begin{tabular}{|c|c|c|c|c|c|c|c|c|c|c|}
\hline Case & Gender & Symptomatic & $\begin{array}{c}\text { Age at } \\
\text { time of } \\
\text { operation }\end{array}$ & $\begin{array}{c}\text { Smoker/ } \\
\text { pulmonary/ } \\
\text { renal/cardiac } \\
\text { status* } \\
\end{array}$ & $\begin{array}{c}\text { Hypertension } \\
\text { status* }\end{array}$ & $\begin{array}{l}\text { History of } \\
\text { vascular } \\
\text { disease } \\
\text { or cancer }\end{array}$ & $\begin{array}{c}\text { No. of } \\
\text { SMFM } \\
\text { devices } \\
\text { implanted } \\
\end{array}$ & $\begin{array}{c}\begin{array}{c}\text { Delivery } \\
\text { complications }\end{array} \\
\end{array}$ & $\begin{array}{l}\text { Postoperative } \\
\text { complications }\end{array}$ & $\begin{array}{c}\text { Patient } \\
\text { alive }\end{array}$ \\
\hline 1 & Male & N/A & $63 \mathrm{y}$ & N/A & N/A & No & 2 & No & No & Yes \\
\hline 2 & Female & Yes & $85 \mathrm{y}$ & $\begin{array}{l}\text { Pulmonary status: } \\
\text { 2, pleural } \\
\text { effusion on the } \\
\text { left hemithorax }\end{array}$ & 0 & No & 1 & No & No & $\begin{array}{l}\text { No, died } \\
\text { July 23, } \\
\text { 2013, of } \\
\text { pulmonary } \\
\text { embolism }\end{array}$ \\
\hline 3 & Female & N/A & $76 y$ & N/A & N/A & $\begin{array}{l}\text { Polyserositis; } \\
\text { angioedema; } \\
\text { hypothyroid }\end{array}$ & 3 & No & $\begin{array}{l}\text { Hematuria and UTI; } \\
\text { reintervention } \\
\text { April 24, } 2012 \\
\text { with } 2 \text { SMFMs }\end{array}$ & Yes \\
\hline 4 & Female & Yes & 83 y & $\begin{array}{l}\text { Nonsmoker, } \\
\text { cardiac } \\
\text { status: } 3\end{array}$ & 3 & $\begin{array}{l}\text { Previous AAA } \\
\text { open repair; } \\
\text { coronary }\end{array}$ & 2 & $\begin{array}{l}\text { Proximal } \\
\quad \text { foreshortening }\end{array}$ & $\begin{array}{l}\text { Reintervention } \\
\quad \text { May 28, } 2014\end{array}$ & $\begin{array}{l}\text { No, died } \\
\text { July } 27 \text {, } \\
2014\end{array}$ \\
\hline 5 & Male & No & 51 y & $\begin{array}{l}\text { Nonsmoker, had } \\
\text { only } 1 \text { kidney }\end{array}$ & 0 & $\begin{array}{l}\text { Renal cell } \\
\text { carcinoma }\end{array}$ & 1 & No & No & Yes \\
\hline 6 & Male & No & $72 \mathrm{y}$ & N/A & N/A & No & 3 & $\begin{array}{l}\text { Proximal } \\
\quad \text { foreshortening }\end{array}$ & N/A & Yes \\
\hline
\end{tabular}

SMFM, Streamliner Multilayer Flow Modulator; N/A, not available; UTI, urinary tract infection; AAA, abdominal aortic aneurysm. *Society of Vascular Surgery comorbidity score.

Simulation I. The number and exact positioning of the SMFM stents were based on the postoperative data.

Simulation II. The SMFM stent was repositioned within the correct landing zone for the proximal foreshortening cases (cases 4 and 6). Two SMFM stents were repositioned along the whole length of the aneurysm for case 5 instead of only 1 stent as was the case in Simulation I, with an overlap of $3 \mathrm{~cm}$ occurring along the mid-length.

Simulation III. The influence of overlapping stent meshes covering the branch regions for case 1 ( 1 vs 2 overlapped stent meshes) and case 4 ( 1 vs 3 overlapped stent meshes) was investigated.

\section{Modeling the Blood Hemodynamics}

The lumen volume represented the fluid domain that was discretized in smaller volumes, which defined a mesh within the ICEM software (Ansys ICEM computational fluid dynamics v15.0), as shown in Figure 2, $C$. A total of 1 to 5 million tetrahedral elements composed the meshes used to capture the complexity of the aortic arch and stent geometries for the preoperative and postoperative cases. The governing equations of pulsatile blood motion, derived from the Navier-Stokes equations, were solved in Ansys (Ansys CFX solver v15.0) by the coupled algebraic multigrid approach, with finite volume domain discretization. A realistic resting flow rate waveform (Figure 2,D) was applied at the aortic root called the "inlet region," and a resting pressure waveform (Figure 2,D) was defined at the arch branches and descending aorta called the "outlet regions." ${ }^{, 3,4} \mathrm{~A}$ no-slip boundary condition was assigned at the SMFM device struts and the aortic wall. The blood was modeled as incompressible, non-Newtonian, and homogenous with a density of $1050 \mathrm{~kg} / \mathrm{m}^{3}$ and a dynamic viscosity described by the Carreau-Yasuda model (Equation 1) for blood shearthinning behavior passing through the stent filament. ${ }^{5,6}$

$$
\frac{\mu-\mu_{\infty}}{\mu_{0}-\mu_{\infty}}=\left[1+(\lambda \cdot \dot{\gamma})^{a}\right]^{(n-1) / a}
$$

Equation 1,

where $\dot{\gamma}$ denotes the scalar shear rate. The Carreau-Yasuda parameters, viscosities $\mu_{0}$ and $\mu_{\infty}-$ lower and upper ends of the shear rate range and $\lambda, n$, $a$ for the transition between these extreme conditions, at $37^{\circ} \mathrm{C}$ are shown in
Table $3{ }^{7}$ Five cardiac cycles were required for each simulation setup to achieve pulse cycle independence, with a time step size of 0.01 seconds. Rigid wall and laminar flow boundary conditions were assigned to all models. Mesh independence was achieved when changes in the outlets' maximum velocity measurements were less than $2 \%$ between successive meshes. The convergence criteria for mass and momentum residuals used were $1 \times 10^{-4}$ and $1 \times 10^{-6}$, respectively. The computational analysis was performed on a 64-bit MSI mobile workstation (CPU: Intel Core i7, eight core $3.67 \mathrm{GHz}$ with $32 \mathrm{~GB}$ of RAM). The time for 1 simulation took 150 hours. To visualize the blood flow through each patient model at systolic pressure, blood velocity was plotted with colored 3-dimensional lines, called "streamlines." They show the flow patterns through the aneurysm. The colored scale indicates how fast the blood is flowing through the aneurysm, from low flow colored blue to high flow colored red.

\section{RESULTS}

\section{Simulation I}

Figures 3 and 4 show the simulation results for the preoperative and postoperative cases based on the acquired medical images. All cases showed improved streamlining of the blood flow with a helical motion and increased recirculation within the aneurysmal sac. Case 5 showed high blood velocity profiles toward the top wall within the sac region (Figure 4). Table E2 shows the percentage difference in branch outflows between the preoperative and postoperative cases. Five of the 6 cases showed a $5 \%$ to $24 \%$ increase in branch outlet flow rates. Only the compassionate case (case 5) had reduced branch outlet flow rates within the left common carotid artery and left subclavian artery branches (reduction of $2 \%$ and $10 \%$, respectively). The corresponding dynamic pressures caused by the blood impacting against the wall are shown in Figures E1 (cases 1-3) and 


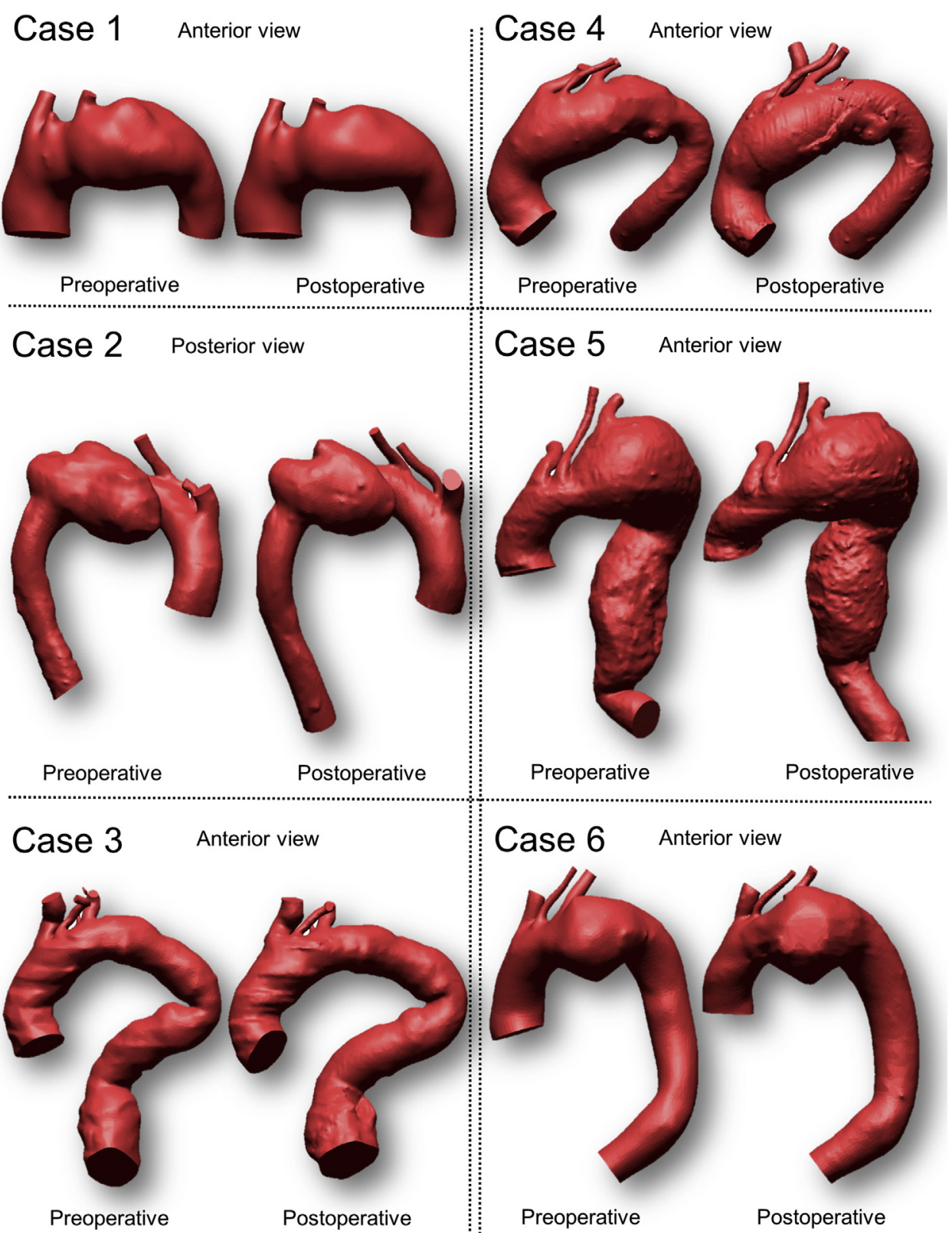

FIGURE 1. Patient-specific 3-dimensional reconstructed anatomies from computed tomography images showing the 6 diseased aortic arches in the preoperative and postoperative states. Cases 1,2, 4, and 6 represent arch aneurysms (case 2 is shown in a posterior view to allow a better exposure of the aneurysm sac). Cases 3 and 5 represent a Crawford type I TAAA.

E2 (cases 4-6). For the postoperative cases (Simulation I), there was a reduction in aortic wall peak dynamic pressures of $23 \%$ to $66 \%$ for cases 1 to 4 , with increased pressures of $58 \%$ and $16 \%$ for cases 5 and 6 , respectively.

\section{Simulation II}

The ideal positioning of the SMFM for cases 4 to 6 is shown in Figures E2 and E3 for the aortic wall dynamic pressures and blood velocity streamlines, respectively. Further decreases in wall dynamic pressures were obtained when compared with the postoperative results of Simulation
I. Only case 5 still had an increase of $12 \%$ when compared with the preoperative state. This further reduction in wall dynamic pressure for the repositioned stents was due to further increases in the streamlining effect as shown in Figure E3. There were further increases and rebalancing of the branch outlet flow rates as shown in Table E2.

\section{Simulation III}

The influence of the double and triple stent overlapping for cases 1 and 4 on the branch outflow is shown in Figure E4. The mean branch outflow percentage increases were 


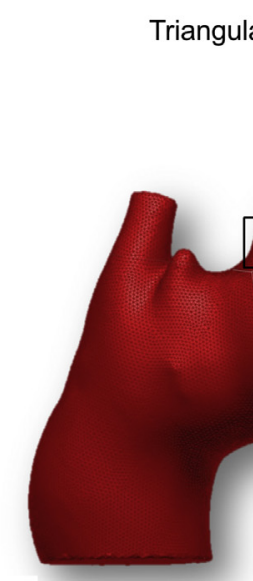

A

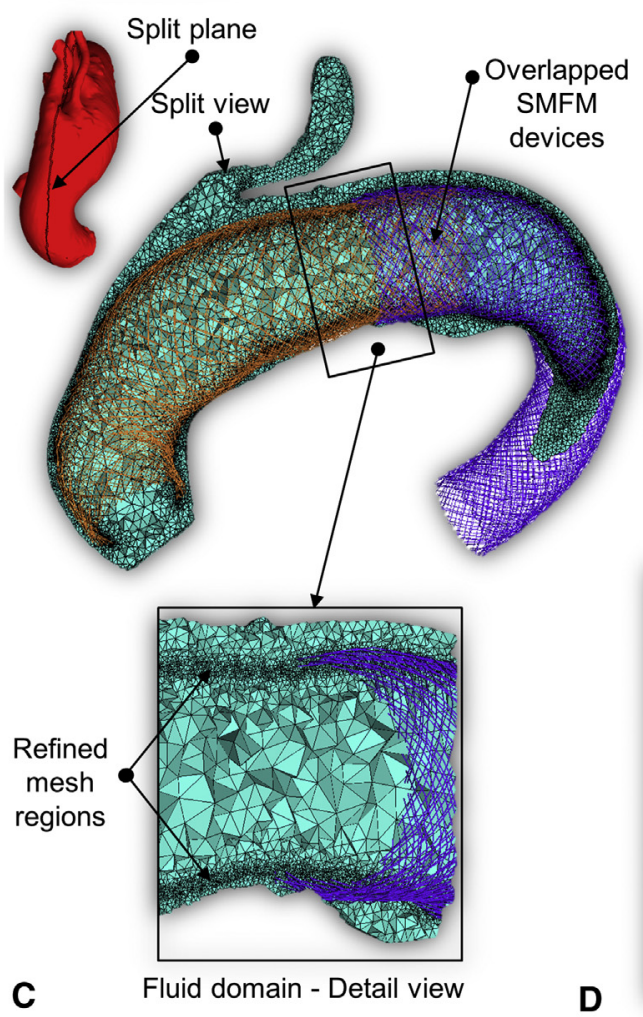

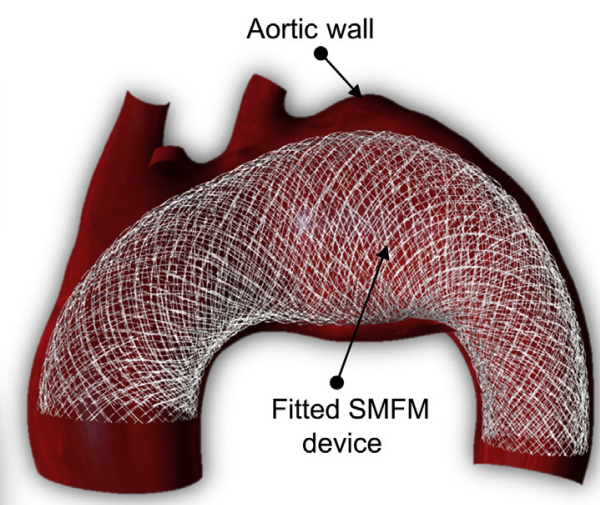

B
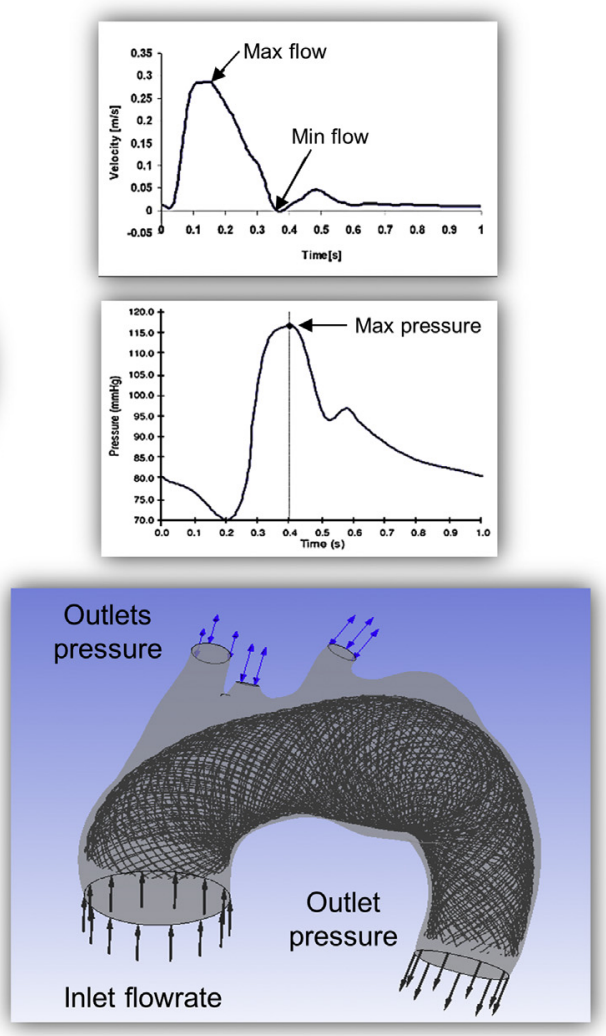

FIGURE 2. Computational fluid dynamics workflow from medical data to blood flow simulation setup. A, Aortic arch 3-dimensional geometry represented by a volume enclosed in a triangulated surface. B, SMFM (Cardiatis, Isnes, Brussels, Belgium) device; spatial representation as fitted through a diseased aortic arch. C, Fluid domain discretization of an aortic arch model fitted with 2 overlapped SMFM devices. D, Realistic boundary conditions applied at the inlet (flow waveform) and outlets (pressure waveform). SMFM, Streamliner Multilayer Flow Modulator.

$19.3 \%$ for the double stent overlapping and $22 \%$ for the triple stent overlapping (Table E3). Increasing the number of overlapped stents along the branch vessels further balances out the branch outflows with increased flow rates.

\section{Clinical Outcomes of Cases Done Under Instructions for Use Versus Outside of Instructions for Use}

Table E3 shows a direct comparison of clinical outcomes between cases performed under IFU (cases 1-3) versus the cases performed outside instructions for use (OIFU) (cases 4-6) at 1-year follow-up. Results show the total volume percentage changes at 1-year follow-up, with a maximum decrease of $23 \%$ for cases performed under IFU and a maximum increase of $33 \%$ for cases performed OIFU. The dynamic pressure acting on the aneurysm wall was reduced by a mean of $50 \%$ for the IFU cases and increased by a mean of $17 \%$ for the OIFU cases (Simulation I, Table E3). Branch outflows were increased by up to $23 \%$ (IFU 
TABLE 2. Preoperative and postoperative anatomic measurements of the 6 aortic arch aneurysms

\begin{tabular}{|c|c|c|c|c|c|c|c|}
\hline Case no. & CT scan & Maximum diameter, cm & Length, cm & Lumen volume, $\mathrm{cm}^{3}$ & ILT volume, $\mathrm{cm}^{3}$ & Total volume, $\mathrm{cm}^{3}$ & ILT/lumen ratio, $\%$ \\
\hline \multicolumn{8}{|l|}{ IFU } \\
\hline 1 & Pre & 6.70 & 9.00 & 202.24 & 85.87 & 288.11 & 42 \\
\hline 1 & Post & 4.10 & 6.00 & 135.58 & 87.05 & 222.63 & 64 \\
\hline 2 & Pre & 4.83 & 9.43 & 125.62 & 8.29 & 133.91 & 7 \\
\hline 2 & Post & 4.15 & 8.19 & 83.43 & 19.74 & 103.17 & 24 \\
\hline 3 & Pre & 3.93 & 3.91 & 34.32 & 12.25 & 46.57 & 36 \\
\hline 3 & Post & 3.67 & 2.62 & 28.96 & 13.57 & 42.53 & 47 \\
\hline \multicolumn{8}{|l|}{ OIFU } \\
\hline 4 & Pre & 5.42 & 11.52 & 212.58 & 34.26 & 246.84 & 16 \\
\hline 4 & Post & 5.19 & 13.72 & 206.43 & 36.51 & 242.94 & 18 \\
\hline 5 & Pre & 6.85 & 20.96 & 386.93 & 100.19 & 487.12 & 26 \\
\hline 5 & Post & 7.85 & 21.64 & 492.67 & 107.62 & 600.29 & 22 \\
\hline 6 & Pre & 5.17 & 5.44 & 110.50 & 52.50 & 163.00 & 47 \\
\hline 6 & Post & 5.78 & 5.12 & 156.04 & 60.70 & 216.74 & 39 \\
\hline
\end{tabular}

$C T$, Computed tomography; $I L T$, intraluminal thrombus; IFU, instructions for use; $O I F U$, outside instructions for use.

cases) because of correct positioning of the SMFM stent and by up to $17 \%$ (OIFU cases) because of Failure Mode I.

\section{DISCUSSION}

As far as the authors are aware, this is the first study that computationally assessed the preoperative and postoperative hemodynamic effects that the SMFM device had on 6 aneurysmal cases. Computational techniques are becoming more prevalent in device design and development, because the SMFM proved to be a useful tool that can make accurate predictions of the blood flow pathways and pressures within the aorta after endovascular aortic repair. Our computational findings were compared with the clinical outcomes reported at 12-month follow-up for all 6 cases. This study compared the simulated hemodynamics within the sac region with the aortic sac behavior documented within the postoperative 1-year follow-up. The preoperative and postoperative (12-month follow-up) geometries were simulated as described in Simulation I with the velocity streamlines (Figures 3 and 4 ) and dynamic pressures (Figures E1 and E2) calculated. Four of the 6 cases (cases 1-3 and 5) were positioned correctly with no proximal or distal stent foreshortening. Cases 1 to 3 showed favorable clinical outcomes (Table 2) with reductions in maximum diameter and volume of $7 \%$ to $39 \%$ and $9 \%$ to $23 \%$, respectively.

On the basis of our computational fluid dynamic simulations and compared with the preoperative results, cases 1 and 2 showed improved streamlining of the flow in a helical formation with reduced dynamic pressures and increased recirculation within the aneurysmal sac region, thus promoting

TABLE 3. Carreau-Yasuda parameters to model the non-Newtonian characteristic of blood at $37^{\circ} \mathrm{C}^{5,6}$

\begin{tabular}{lcccc}
\hline $\boldsymbol{\mu}_{\mathbf{0}}[\mathrm{Pa} \cdot \mathrm{s}]$ & $\boldsymbol{\mu}_{\infty}[\mathrm{Pa} \cdot \mathrm{s}]$ & $\boldsymbol{\lambda}_{(\mathrm{s})}$ & $\boldsymbol{n}$ & $\boldsymbol{a}$ \\
\hline 0.16 & 0.0035 & 8.2 & 0.2128 & 0.64 \\
\hline
\end{tabular}

further ILT formation, as was found at the 12-month follow-up (Table 2). In case 3, 3 overlapping SMFM devices were positioned from the ascending aorta (zone 0) to the distal side of the aneurysm (zone 5). The positioning of these stents caused the aortic arch to favorably remodel its shape (Figures 3 and E1), which aided in eliminating the recirculation region with a more uniform flow field (Figure 3 and Central Figure) that resulted in a reduction in saccular volume (Table 2). The analysis predicted increases in branch outflows for these successful cases (Table E2), which agrees with Henry and colleagues, ${ }^{2}$ who reported excellent branch vessel patency rates for SMFM-treated cases.

It is important to make a clear distinction between case classification of outside of instructions for use ${ }^{8}$ and OIFU. OIFU means that cases were performed within the indications for use; however, technical issues during the intervention precluded delivery of the stent to the target area, mainly because of physician preference. Cases 4 to 6 were classified as OIFU for the following reasons: Case 4 was OIFU because of the tortuosity of the arch, which led to stent proximal foreshortening during positioning, case 5 had a giant long shaggy aorta, and in case 6 the stent did not cover normal to normal aorta. Patient 4 had a descending aorta with an "S-shape" for zones 4 and 5, which caused foreshortening of the distal end of the SMFM, with $50 \%$ radial size reduction. Another SMFM was then positioned inside the distal end stent $(3 \mathrm{~cm})$ to open it and bring it in contact with the lumen wall. There were no technical issues in positioning the SMFM stent for the compassionate case (case 5). Unfortunately, this case had an unfavorable clinical outcome with further aneurysmal expansion (Table 2). The reason for this failure as shown by our simulations is that the main velocity component is still impacting against the upper wall and is not contained by the SMFM multilayered structure (Figure 4) as was for cases 1 to 3 . This led to an increased dynamic pressure acting against the arterial wall (Figure E2) causing further volume expansion of 
Case 1 Anterior view

Anterior view

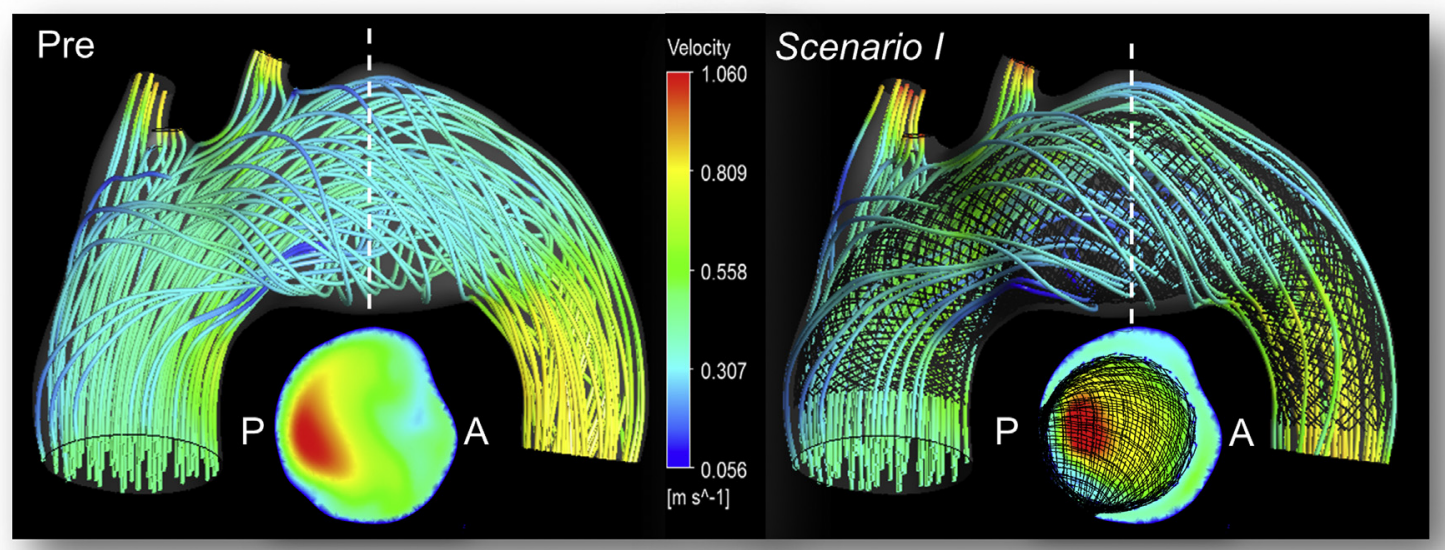

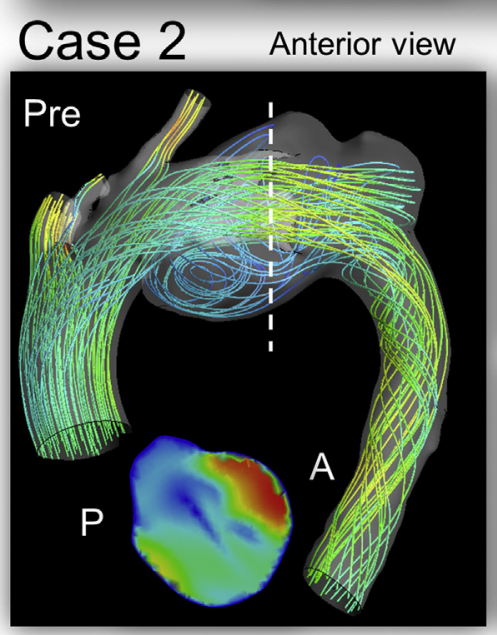

Case 3

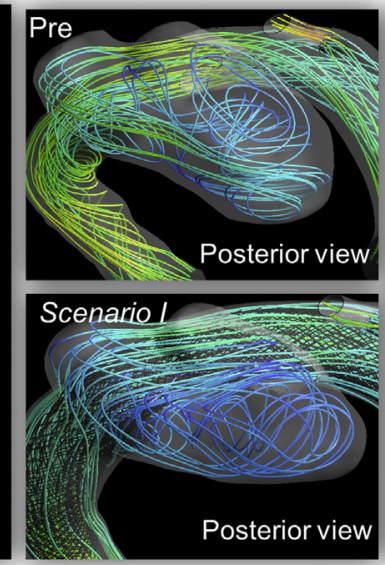

Posterior view

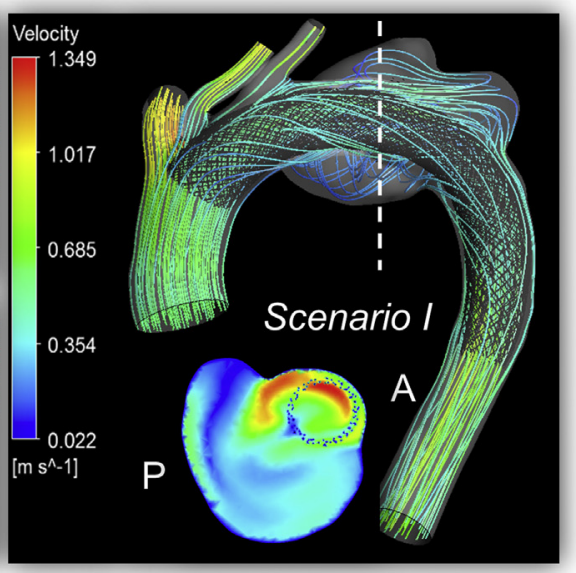

Anterior view

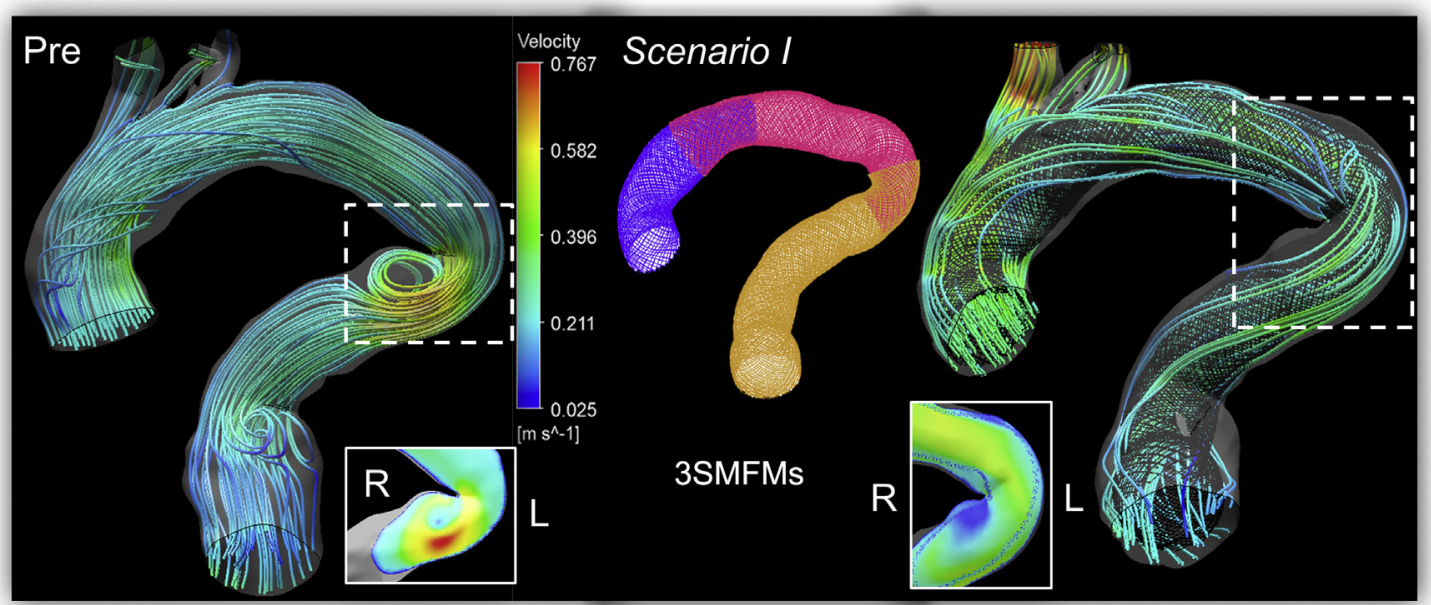

FIGURE 3. Blood flow simulation results for the preoperative scenario and scenario I in cases 1 to 3 , showing velocity streamlines and aortic arch aneurysms in cross-section velocity contour plots colored by velocity magnitude at peak flow cardiac cycle (time step t $=0.17$ seconds), with SMFM devices overlapping positioning in 3-dimensional display for clarification purposes in case 3. P, Posterior; A, anterior; SMFM, Streamliner Multilayer Flow Modulator; $R$, right; $L$, left.

$23 \%$ (Table 2) with reduced branch outflows for the left common carotid artery and left subclavian artery vessels (Table E2).
The SMFM devices were not positioned correctly for cases 4 and 6, with proximal stent foreshortening occurring for both, leading to Failure Mode I. The fusiform shape of 
Case 4 Anterior view

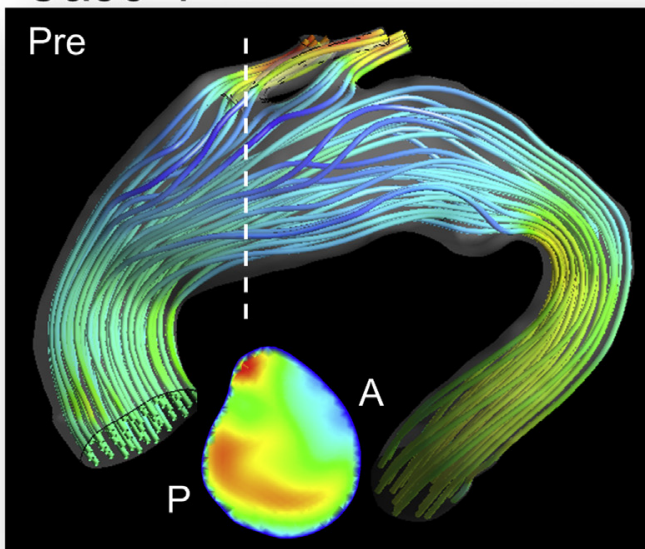

Anterior view

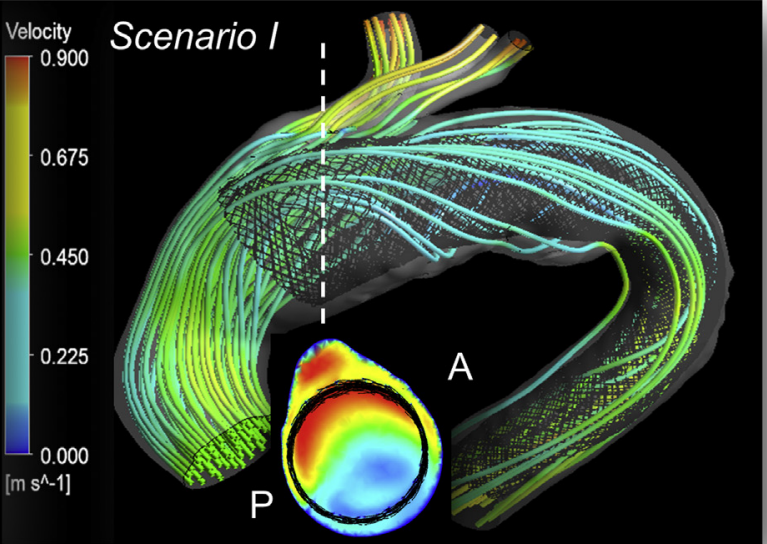

Right view

Case 5 Right view

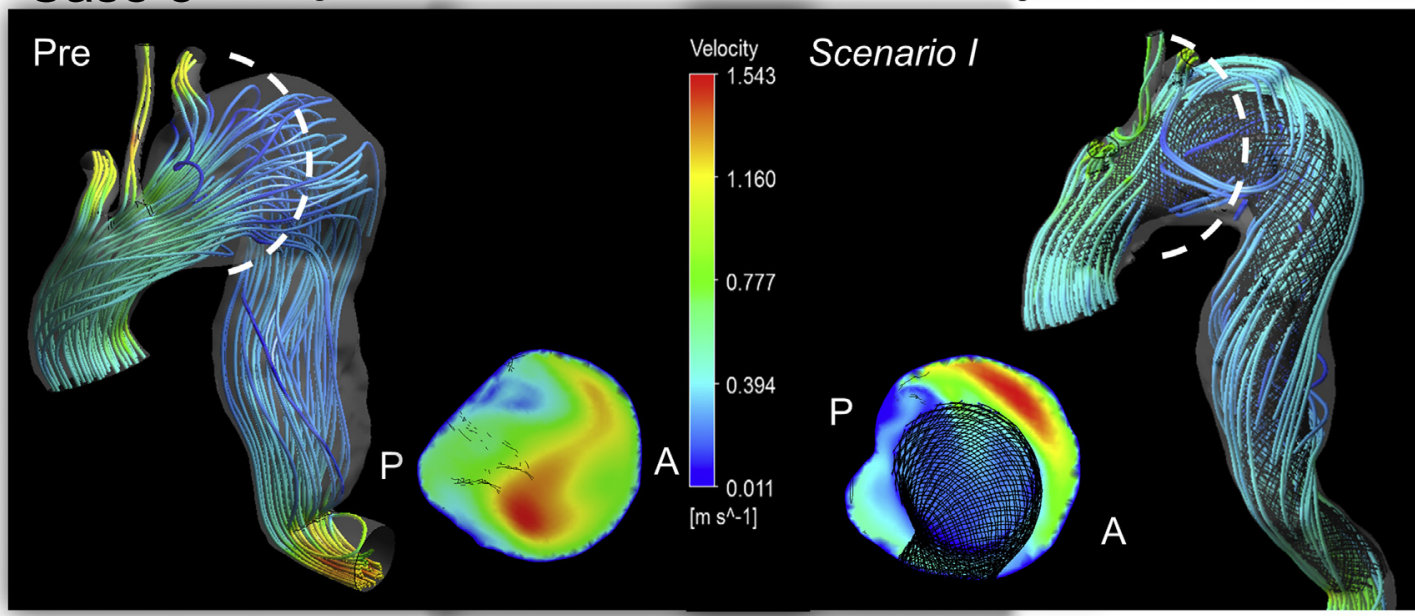

Case 6 Anterior view

Anterior view

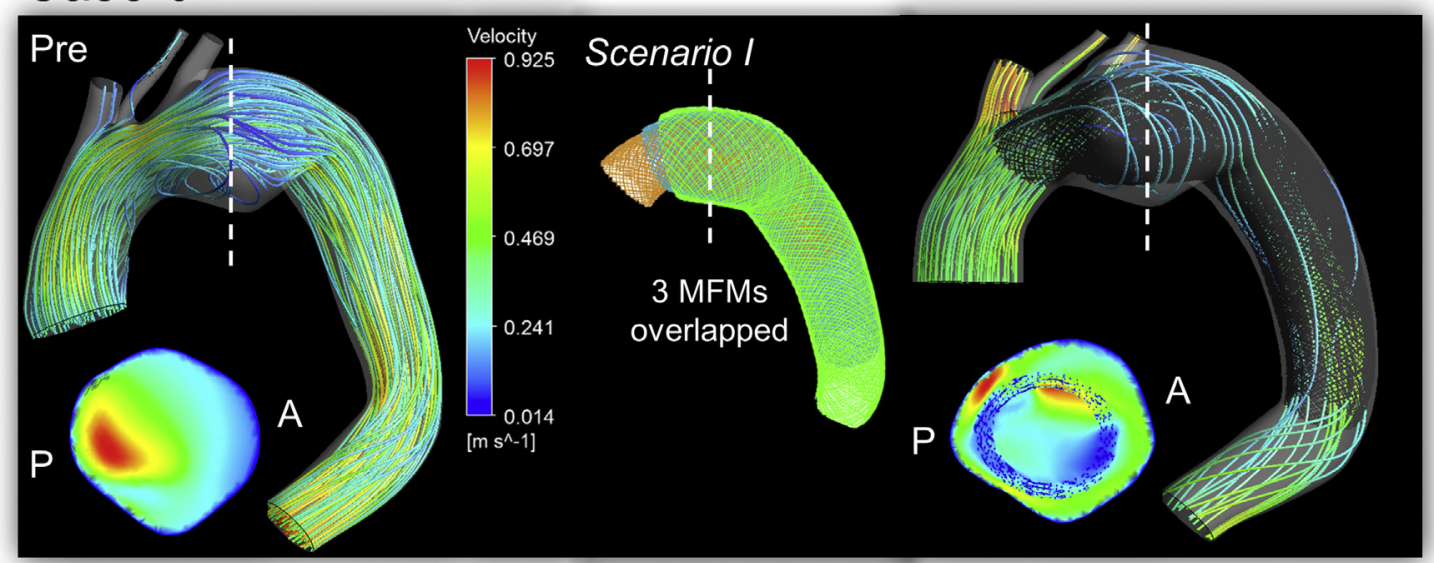

FIGURE 4. Blood flow simulation results for the preoperative scenario and scenario I in cases 4 to 6 , showing velocity streamlines and aortic arch aneurysms in cross-section velocity contour plots colored by velocity magnitude at peak flow cardiac cycle (time step $\mathrm{t}=0.17$ seconds), with SMFM devices overlapping positioning in 3-dimensional display for clarification purposes in case 6. P, Posterior; A, anterior; MFM, Multilayer Flow Modulator.

the aneurysm (case 4) in combination with the flow modulation effect of the SMFM stabilized the aneurysm volume over 12 months. Although it was a positive experience and an exception, we had to point out that this is not how the IFU recommend to use the SMFM device. Similar foreshortening issues have been reported. ${ }^{8,9}$ Sultan and colleagues ${ }^{8}$ reported failure to land the device in the normal aorta in 31 of 38 cases treated OIFU, in which aneurysm-related deaths 
were $71.1 \%$. There were mixed clinical outcomes for both cases during the 12-month follow-up with a decrease in maximum diameter and volume occurring only for case 4 , of $4 \%$ and $2 \%$, respectively, whereas case 6 had an increase of $12 \%$ and $33 \%$ increase in maximum diameter and total volume, respectively (Table 2).

Our simulations (Figure 4) confirmed that the majority of the flow is contained within the SMFM device for case 4 , whereas there are still high flow rates occurring within the sac region for case 6 . This higher flow rate within the sac region generated an increased dynamic pressure $(+16 \%)$ along the arterial wall (Figure E2) when compared with the preoperative state that contributed to the continued sac enlargement. Case 5 was treated with 1 long SMFM stent that was positioned within the IFU, but did not improve the flow field within the sac region, which led to the reported aneurysm volume expansion of $23 \%$.

In an attempt to predict the best possible clinical outcomes for cases 4 to 6 , stents were virtually repositioned as described in Simulation II. For cases 4 and 6, the virtual stent repositioning eliminated the issues of stent foreshortening, whereas positioning 2 connected stents that were overlapped within zone 4 by $6 \mathrm{~cm}$ increased the stent radius of curvature throughout the aneurysm for case 5. Further streamlining of the flow was found for these virtual repositioned stent cases with a corresponding decrease in dynamic pressures when compared with the treated cases (Simulation I) and further rebalancing of the branch outlet flow rates (Table E2).

These positive improvements in the hemodynamic effects may have promoted a further reduction in aneurysmal volume growth in case 4 with the possibility of stabilizing or reducing the aneurysmal growth in cases 5 and 6. Further simulations are required to assess the best stenting combination for compassionate cases, such as case 5 , to provide the best clinical outcomes. One reported limitation, is that the SMFM device requires an accurate delivery deployment system with careful attention paid to issues such as foreshortening and maximum stent overlap length and oversizing. ${ }^{9}$

There were no adverse effects on branch patency of overlapping a number of SMFM devices across the arch branching vessels. Further increases in branch outflows were found with increasing number of SMFM devices across the branching vessels as shown in Figure E4. The multilayers within each strut of the SMFM device allow flow to easily pass through without affecting branch patency rates even though stent permeability was reduced. Clinical reviews of SMFM technology have reported full branch patency rates with multiple overlapping stents. ${ }^{2,9}$ A clinical review on the performance of the SMFM by Sultan and Hynes ${ }^{9}$ found all 202 side branches were patent for the 55 treated cases reported. Our simulations found further diminishing flow within the sac region thus promoting ILT formation. These findings are in agreement with Doerfler and colleagues, ${ }^{10}$ who, after treating an aneurysm of the distal vertebral artery, concluded that placing 1 stent inside the other may result in significant hemodynamic changes with accelerated aneurysm thrombosis.

Reports for long-term follow-ups for a variety of aneurysm types showed that patients treated with the SMFM had early good postoperative outcomes. ${ }^{2,9,10}$ Currently, 307 cases have been submitted and analyzed through the SMFM Global registry. ${ }^{11}$

Level 1 evidence from patient-level meta-analysis has proven that cases performed under indications for use have positive outcomes, with an 18-month aneurysmrelated survival of $93.3 \%$ with no renal impairment, paraplegia, or stroke. ${ }^{12}$ This seminal publication limited the indication for intervention on thoracoabdominal aneurysm to a maximum diameter of $6.5 \mathrm{~cm}$ and broadened the indications for use to include Stanford Type A and B aortic dissection.

None of the 6 cases within this study reported aneurysm rupture after the 12-month follow-up except that the stent foreshortened within the treated aortic arch aneurysm (case 6) and the TAAA Crawford type I (case 5) showed continued aneurysmal expansion. The simulations showed that all vessels were still patent in all 6 cases after the various combinations of SMFM placement.

The placement for best clinical outcomes requires the device to be proximally and distally in contact with the normal aortic wall with a minimum of $3 \mathrm{~cm}$ of stent arterial wall contact as indicated by the IFU. Failure to correctly plan the positioning of SMFM device as was in cases 4 and 6 will result in severe stent foreshortening leaving the proximal end stent suspended within the sac region leading to Failure Mode I, thus inhibiting ILT formation. These 2 foreshortening cases had device oversizing of less than $15 \%$ because of the unavailability of larger devices. Currently, a 45-mm device with a 50-mm dumbbell-shaped proximal cuff is now commercially available, which would allow operators the choice of a greater oversizing range. A $15 \%$ to $25 \%$ device oversize may improve the clinical success rate. For best practice, we recommend the following principle: "The longer the stent, the better the outcome." This would allow the device to better adapt to the diseased lumen shape.

Caution is required when treating aneurysms with lengths greater than $20 \mathrm{~cm}$ and volumes greater than $400 \mathrm{~cm}^{3}$, because the ratio of collagen to elastin, in the walls of the aneurysm, is increased beyond retrieve and no aortic wall elasticity is available for modulation.

By incorporating 2 SMFM stents overlapped $3 \mathrm{~cm}$ within zone 4 , the radius of curvature was increased within the stent structure, thus favorably improving the flow field. 
The overlapping distance of $3 \mathrm{~cm}$ or greater is critical to maintain a constant diameter and arch profile along the device without adversely affecting the stent geometry, as for the reported treated case.

We learned from the 6 cases that $50 \%$ of the physicians did not choose to implant the SMFM in zone 0 . However, when we performed Simulation II to correct device positioning to the best performance, we conferred that starting in zone 0 will give better streamlining. Simulation III has proven beyond a reasonable doubt that double and triple stenting, over the great vessels of the head and neck, improves the flow. We believe from Simulations I, II, and III that for the best streamlining and modulation of the arch, the stent should start in zone 0 as close as possible to the coronary sinus, taking the outer curvature, and in contact with the ostium of the great vessels of the head and neck. The stent overlapping has to be from zone 3 to 4 with a length between 3 and $6 \mathrm{~cm} .{ }^{8}$

Operator care is required to eliminate the various technical errors, such as incorrect stent placement, foreshortening, inadequate stent overlap lengths, and insufficient numbers of implanted devices. All of these technical concerns must be taken into account when selecting the right patients and the best device combination.

The SMFM device for aortic arch repair study findings mandate the development of 2 device types: one dedicated to the management of aortic arch aneurysms and the second specific to aortic arch dissection. The differences between the 2 will be disease-specific variations in porosity, permeability, and compliance. With further refinement and development, the SMFM device will be applicable to all arch pathologies. Pipeline developments include nano-well surfacing to induce rapid endothelialization and stabilization.

The positive effects on side branch flow demonstrated in the SMFM device for aortic arch repair study are strong indications for the application of the device to enhance visceral and supra-aortic branch perfusion. These benefits extend to the management of renal impairment with alleviation of the need for dialysis, stroke prevention, and slowing the progression of dementia. In addition, its ability to filter blood flow lends itself to applications in embolic protection, which will be particularly efficacious in stroke prevention in patients with atheromatous arches, dilated cardiomyopathy, or cardioembolic sources.

\section{Study Limitations}

Limitations of this study include replication of physiologic pressure and blood flow waveforms on the basis of the literature data and rigid wall analysis in which the aortic wall and stent motion are not taken into account. Because of limited computational resources, a small number of cases and a maximum of 3 overlapped stent configurations were investigated in this study.

\section{CONCLUSIONS}

Our computational analysis showed favorable blood flow patterns within the sac regions induced by the presence of the SMFM device for 4 treated pure aortic arch aneurysms, which may explain the reduction in sac volume at 1-year follow-up. The application of computational techniques is growing and will soon become a vital clinical tool for preoperative planning in selecting the correct device combination for treating these challenging aneurysmal anatomies.

\section{Conflict of Interest Statement}

Authors have nothing to disclose with regard to commercial support.

\section{References}

1. Faure EM, Canaud L, Marty-Ané C, Alric P. Hybrid aortic arch repair for dissecting aneurysm. J Thorac Cardiovasc Surg. 2016;152:162-8.

2. Henry M, Benjelloun A, Henry I, Wheatley G. The multilayer flow modulator stent for the treatment of arterial aneurysms. J Cardiovasc Surg (Torino). 2013;54:763-83.

3. Nichols WW, O'Rourke MF, McDonald DA. Contours of pressure and flow waves in arteries. In: Hodder A, ed. McDonald's blood flow in arteries: theoretic, experimental, and clinical principles. 5th ed. London: Hodder Headline Group; 2005:173.

4. Di Martino E, Mantero S, Inzoli F, Melissano G, Astore D, Chiesa R, et al. Biomechanics of abdominal aortic aneurysm in the presence of endoluminal thrombus: experimental characterisation and structural static computational analysis. Eur J Vasc Endovasc Surg. 1998;15:290-9.

5. Buchanan JR, Kleinstreuer C, Comer JK. Rheological effects on pulsatile hemodynamics in a stenosed tube. Comput Fluids. 2000;29:695-724.

6. Leuprecht A, Perktold K. Computer simulation of non-Newtonian effects on blood-flow in large arteries. Comput Methods Biomech Biomed Eng. 2001;4: 149-63.

7. Abraham F, Behr M, Heinkenschloss M. Shape optimization in steady blood flow: a numerical study of non-Newtonian effects. Comput Methods Biomech Biomed Eng. 2005;8:127-37.

8. Sultan S, Hynes N, Sultan M, MFM Collaborators. When not to implant the multilayer flow modulator: lessons learned from application outside the indications for use in patients with thoracoabdominal pathologies. $J$ Endovasc Ther. 2014;21:96-112.

9. Sultan S, Hynes N. One-year results of the multilayer flow modulator stent in the management of thoracoabdominal aortic aneurysms and type B dissections. J Endovasc Ther. 2013;20:366-77.

10. Doerfler A, Wanke I, Egelhof T, Stolke D, Forsting M. Double-stent method: therapeutic alternative for small wide-necked aneurysms. J Neurosurg. 2004; 100:150-4.

11. Sultan S, Kavanagh E, Stefanov F, Sultan M, Costache V, Elhelali A, et al. Streamliner Multilayer Flow Modulator stents as a therapeutic option in the management of complex thoracoabdominal aortic pathology report from Global SMFM Registry. JICC. 2015;6:77-84.

12. Hynes N, Sultan S, Elhelali A, Diethrich EB, Kavanagh EP, Sultan M, et al. Systematic review and patient-level meta-analysis of the streamliner multilayer flow modulator in the management of complex thoracoabdominal aortic pathology. J Endovasc Ther. 2016;23:501-12.

Key Words: aortic arch, streamliner, multilayer flow modulator, endovascular, aneurysm, volume 
Case 1

Scenario I

\section{Scenario II}

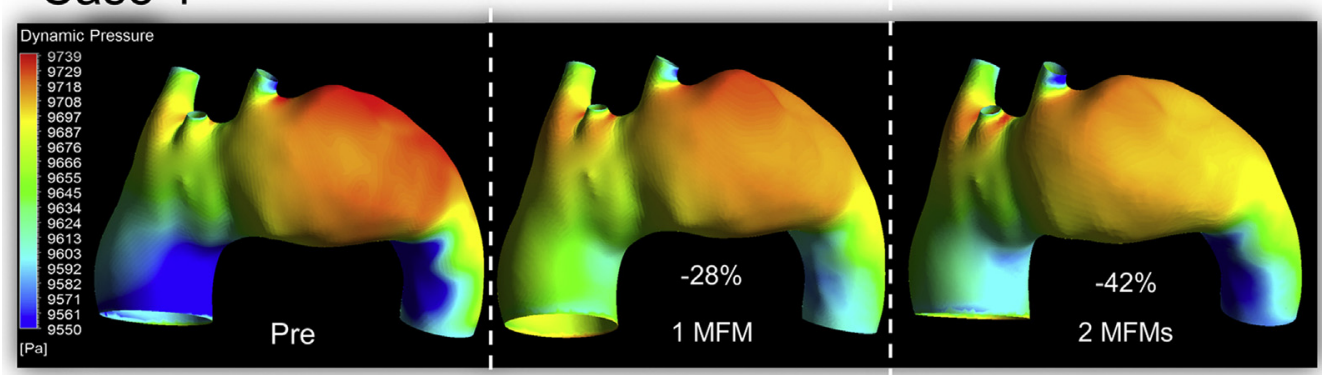

Case 2

\section{Scenario I}

Anterior view Posterior view Anterior view

Posterior view

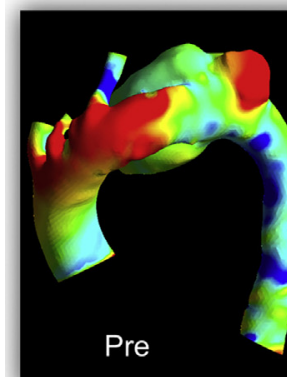
?
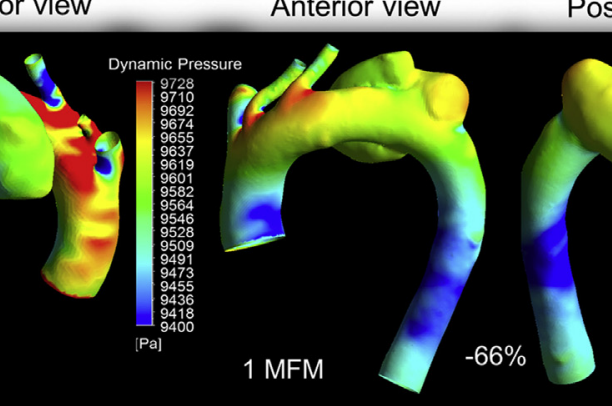

\section{Case 3}

\section{Scenario I}

Anterior view Posterior view
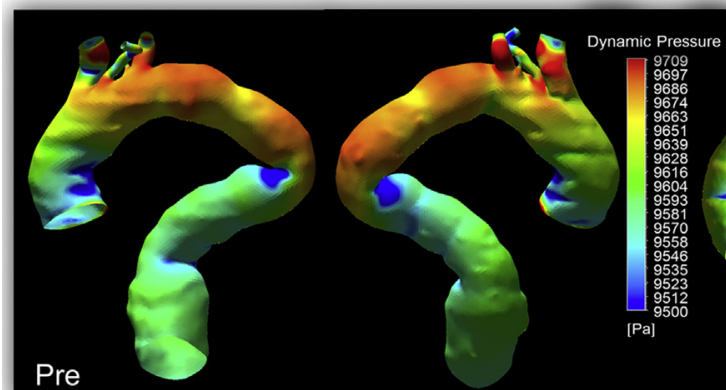

\section{Ant}

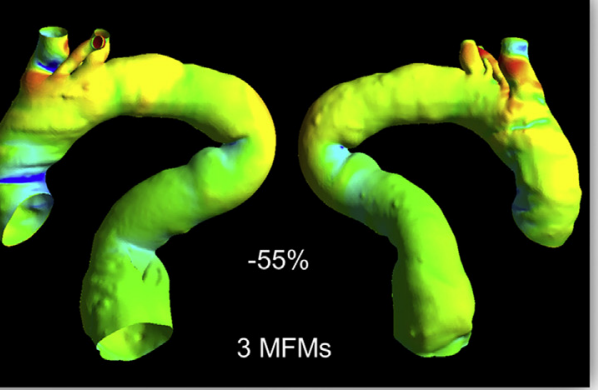

FIGURE E1. Dynamic pressure distribution on the aortic arch wall due to blood flow through the diseased human aortic arch (cases 1-3) at diastolic pressure (time step $\mathrm{t}=0.23 \mathrm{~s}$ ). Pressure contour plots comparison between preoperative and simulated scenarios I and II. MFM, Multilayer Flow Modulator. 
Case 4

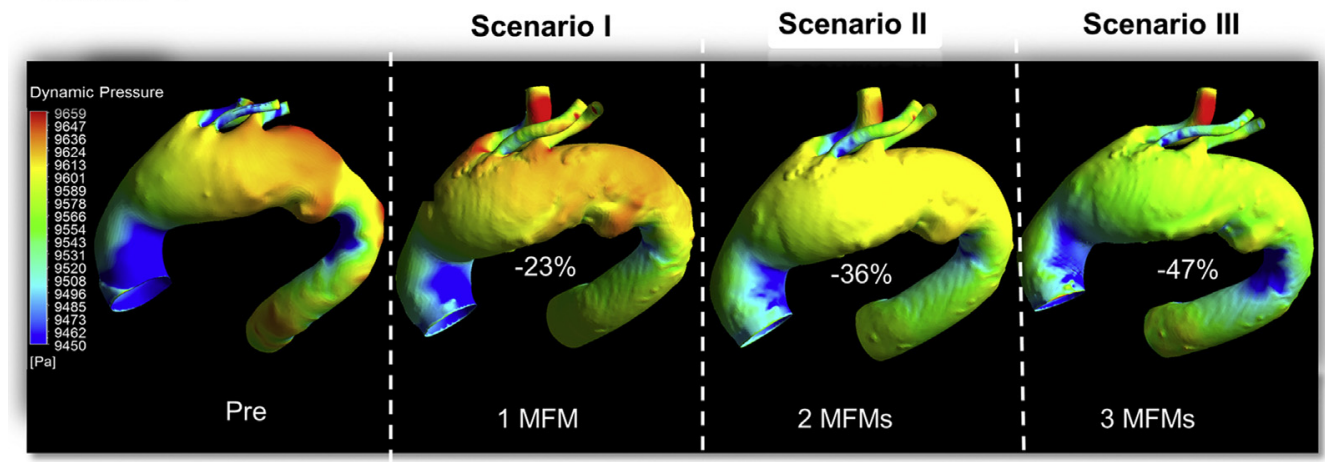

Case 5

Scenario I

Scenario II

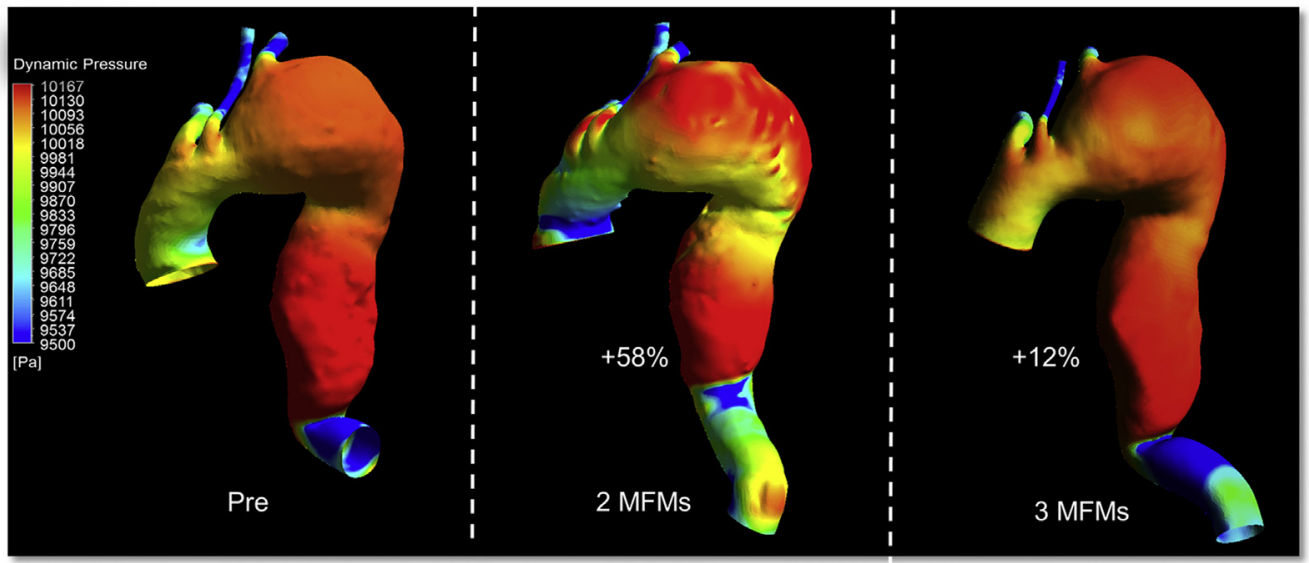

Case 6

Scenario I

Scenario II

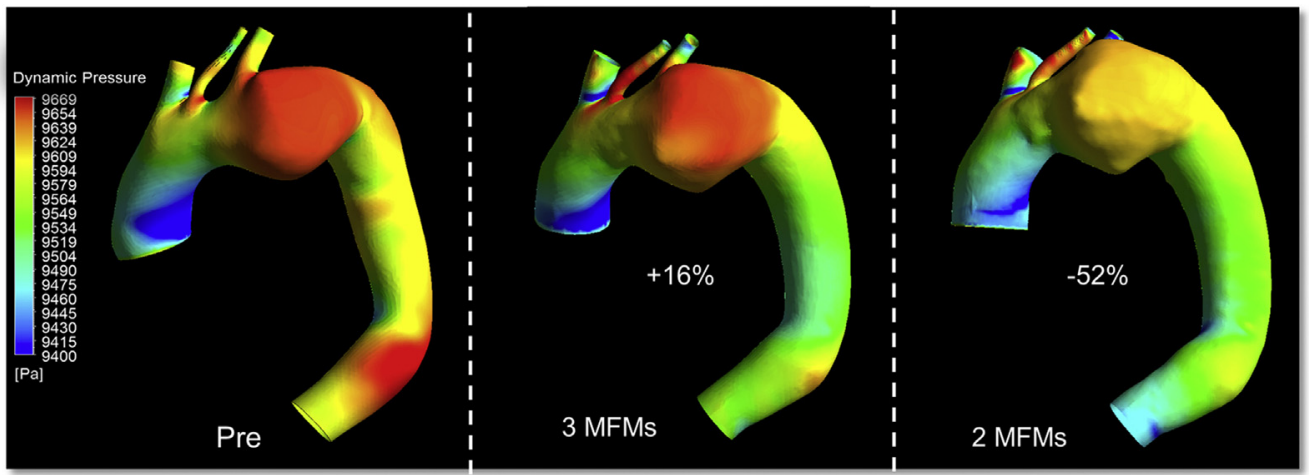

FIGURE E2. Dynamic pressure distribution on the aortic arch wall due to blood flow through the diseased human aortic arch (cases 4-6) at diastolic pressure (time step $\mathrm{t}=0.23 \mathrm{~s}$ ). Pressure contour plots comparison between preoperative and simulated scenarios I, II, and III. MFM, Multilayer Flow Modulator. 


\section{Scenario II (Correct stents positioning)}
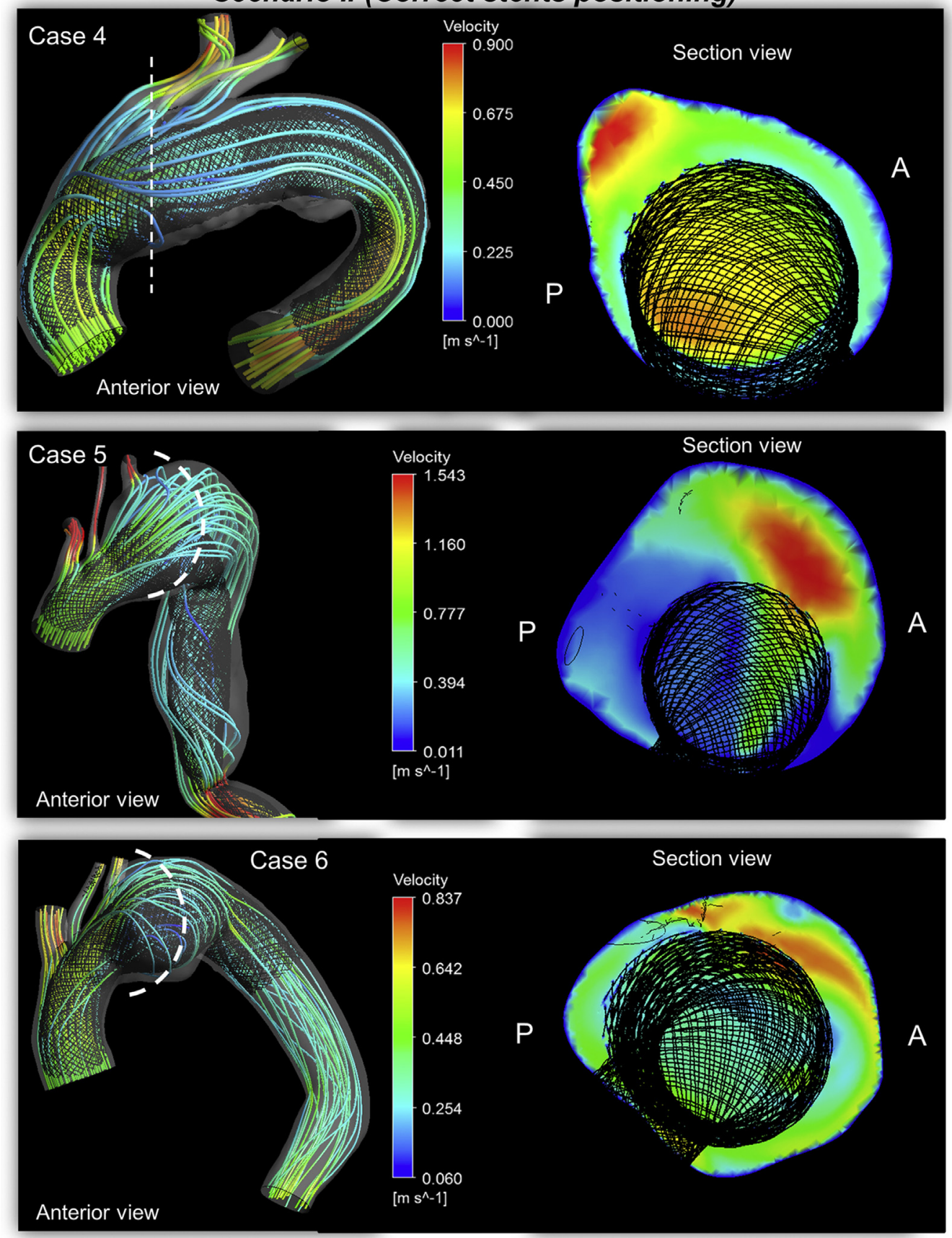

FIGURE E3. Simulated scenario II of blood flow through the diseased human aortic arch with cases 4, 5, and 6, showing the correct SMFM stent (Cardiatis, Isnes, Brussels, Belgium) positioning and velocity streamlines and cross-section velocity contour plots colored by velocity magnitude at peak flow cardiac cycle (time step $\mathrm{t}=0.17 \mathrm{~s}$ ) within the aortic arch aneurysms. $P$, Posterior; $A$, anterior. 


\section{Scenario III (Branch patency)}

Case 1
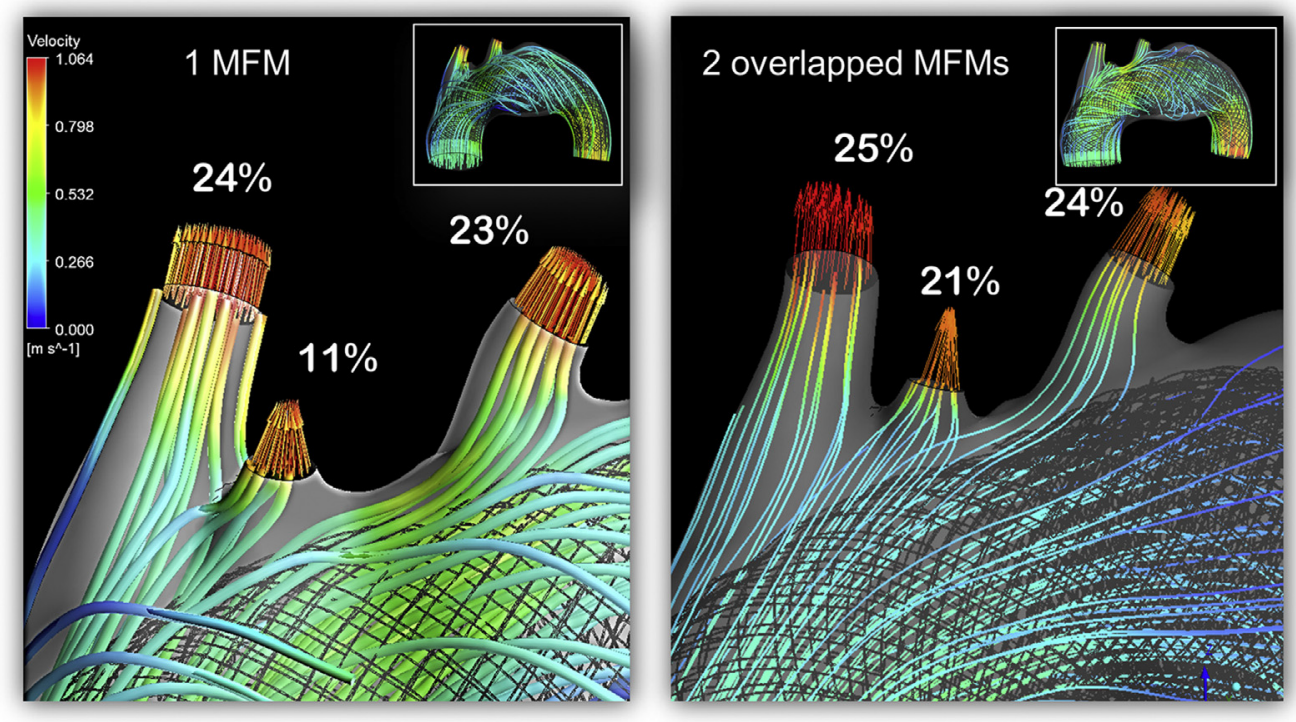

Case 4
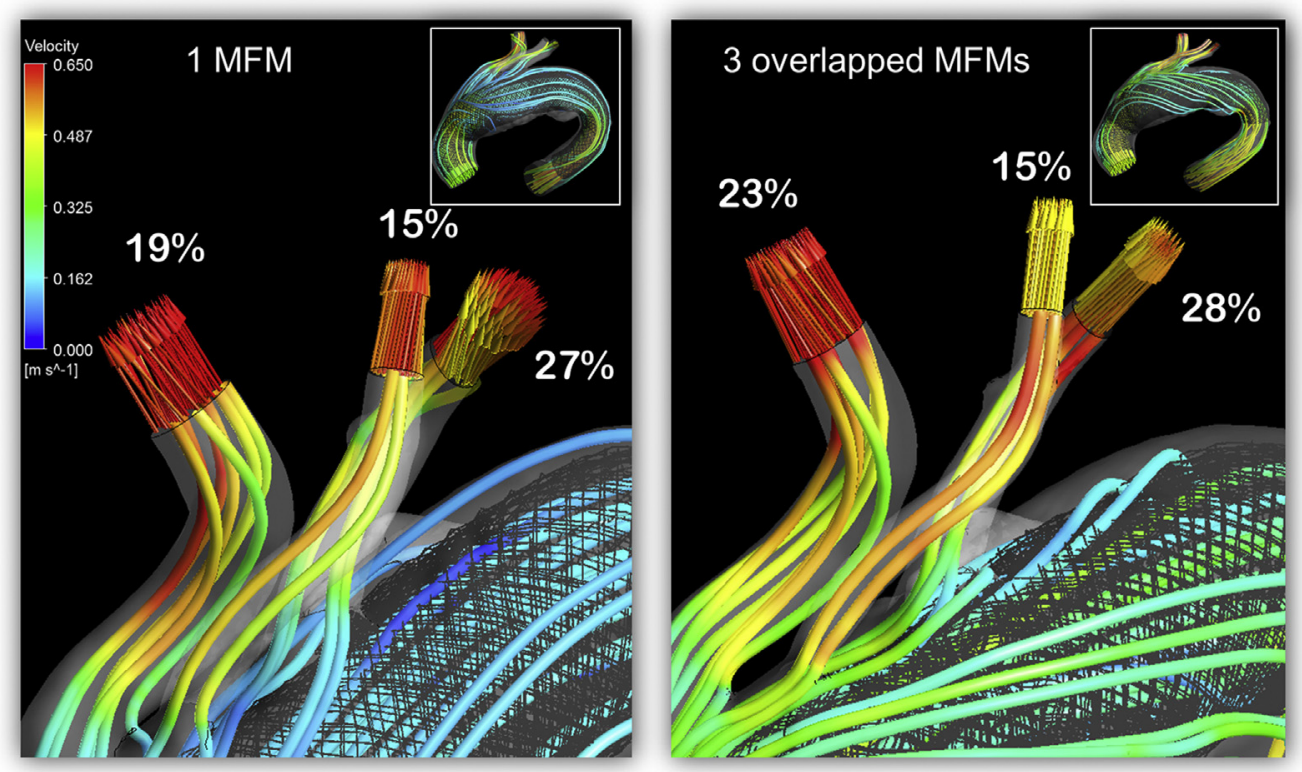

FIGURE E4. Simulated scenario III of blood flow through the diseased human aortic arch with cases 1 and 4 , showing the branch percentage outflows when covered by 1,2, and 3 overlapped SMFM stents (Cardiatis, Isnes, Brussels, Belgium) and velocity streamlines at peak flow cardiac cycle (time step $\mathrm{t}=0.17 \mathrm{~s}$ ). MFM, Multilayer Flow Modulator. 
TABLE E1. Streamliner Multilayer Flow Modulator device sizes with original length and actual length measurements, overlapping length, and total vessel coverage length

\begin{tabular}{|c|c|c|c|c|c|c|c|c|c|c|c|}
\hline \multirow[b]{2}{*}{ Case } & \multicolumn{3}{|c|}{ SMFM 1 length, cm } & \multicolumn{3}{|c|}{ SMFM 2 length, cm } & \multicolumn{3}{|c|}{ SMFM 3 length, cm } & \multirow[b]{2}{*}{ Overlap, cm } & \multirow[b]{2}{*}{ Total vessel cover length, $\mathrm{cm}$} \\
\hline & LO & $\mathbf{L P}$ & D & LO & $\mathbf{L P}$ & D & LO & LP & D & & \\
\hline \multicolumn{12}{|l|}{ IFU } \\
\hline 1 & 10 & 12 & 40 & 20 & 18 & 40 & - & - & - & 4 & 26 \\
\hline 2 & 18 & 20 & 32 & - & - & - & - & - & - & - & 20 \\
\hline 3 & 15 & 18 & 35 & 10 & 12 & 40 & - & - & - & 4 & 31 \\
\hline Mean & 14.3 & 16.7 & 35.7 & 15 & 15 & 40 & & & & 4 & 25.7 \\
\hline \multicolumn{12}{|l|}{ OIFU } \\
\hline 4 & 20 & 24 & 40 & - & - & - & - & - & - & - & 24 \\
\hline 5 & 20 & 22 & 40 & 20 & 27.3 & 40 & - & - & - & 10 & 39.3 \\
\hline 6 & 15 & 18 & 40 & 15 & 18 & 35 & 18 & 20 & 32 & 24 & 36 \\
\hline Mean & 18.3 & 21.3 & 40 & 17.5 & 22.7 & 37.5 & 18 & 20 & 32 & 17 & 33.1 \\
\hline
\end{tabular}

- refers to no simulation results. SMFM, Streamliner Multilayer Flow Modulator; $L O$, original length from catalogue; $L P$, length after positioning; $D$, diameter; $I F U$, instructions for use; $O I F U$, outside instructions for use.

TABLE E2. Maximum outflows percentage increase/decrease measured at the aortic arch main branches in relation to the preoperative state: innominate, left common carotid, and left subclavian arteries

\begin{tabular}{|c|c|c|c|c|c|c|}
\hline \multirow[b]{2}{*}{ Cases } & \multicolumn{3}{|c|}{ Simulation I ( $\%)$} & \multicolumn{3}{|c|}{ Simulation II ( $\%)$} \\
\hline & INNA & LCCA & LSA & INNA & LCCA & LSA \\
\hline \multicolumn{7}{|l|}{ IFU } \\
\hline 1 & +25 & +21 & +24 & - & - & - \\
\hline 2 & +2 & +5 & +16 & - & - & - \\
\hline 3 & +12 & +11 & +17 & - & - & 一 \\
\hline \multicolumn{7}{|l|}{ OIFU } \\
\hline 4 & +17 & +5 & +10 & +19 & +15 & +27 \\
\hline 5 & +4 & -2 & -10 & +37 & +10 & +21 \\
\hline 6 & +16 & +13 & +22 & +17 & +15 & +23 \\
\hline
\end{tabular}

Plus sign refers to increase. Minus sign refers to decrease. — refers to no simulation results. INNA, Innominate artery; $L C C A$, left common carotid artery; $L S A$, left subclavian artery; $I F U$, instructions for use; $O I F U$, outside instructions for use.

TABLE E3. Streamliner Multilayer Flow Modulator device performance changes between instructions for use and outside instructions for use cases

\begin{tabular}{|c|c|c|c|c|c|c|c|}
\hline \multirow[b]{3}{*}{ Case } & \multirow[b]{3}{*}{ Classification } & \multirow[b]{3}{*}{$\begin{array}{c}\text { Follow-up total } \\
\text { volume change, } \%\end{array}$} & \multicolumn{5}{|c|}{ Virtual analysis } \\
\hline & & & \multicolumn{2}{|c|}{ Simulation I } & \multicolumn{2}{|c|}{ Simulation II } & \multirow{2}{*}{$\begin{array}{c}\text { Simulation III } \\
\text { Mean branch } \\
\text { outflows, } \%\end{array}$} \\
\hline & & & $\begin{array}{c}\text { Dynamic } \\
\text { pressure, \% }\end{array}$ & $\begin{array}{c}\text { Mean branch } \\
\text { outflows, \% }\end{array}$ & $\begin{array}{c}\text { Dynamic } \\
\text { pressure, \% }\end{array}$ & $\begin{array}{c}\text { Mean branch } \\
\text { outflows, \% }\end{array}$ & \\
\hline 1 & IFU & -23 & -28 & +23.3 & -42 & - & +19.3 \\
\hline 2 & IFU & -23 & -66 & +7.7 & - & - & - \\
\hline 3 & IFU & -9 & -55 & +13.3 & - & - & - \\
\hline 4 & OIFU & -2 & -23 & +10.7 & -36 & +20.3 & +22 \\
\hline 5 & OIFU & +23 & +58 & -2.7 & +12 & +22.7 & - \\
\hline 6 & OIFU & +33 & +16 & +17 & -52 & +18.3 & - \\
\hline
\end{tabular}

Plus and minus signs refer to an increase and decrease, respectively. — refers to no simulation results. IFU, Instructions for use; OIFU, outside instructions for use. 